\title{
Odour Study with Qualitative and Quantitative Research Methods in Various Districts of Riga
}

\author{
Evita Mužniece-Treija \\ University of Latvia, Faculty of Geography and Earth Sciences Address: Raina Boulevard 19, Riga, LV-1586, \\ Latvia
}

\begin{abstract}
Different emission sources of odours become increasingly important environmental problem which may have a negative impact on human health and quality of life. Human odour perception may be subjective, however on odour perception threshold is considered to be the odorant concentration where at least half of odour assessor's group members confirm the existence of odour, and then it is $1 \mathrm{OU}_{E} / \mathrm{m}^{3}$. Nowadays more and more advanced technologies are used to measure odour concentration. Olfactometer Scentroid SM100 allows users to accurately quantify ambient odour concentration in field. Also this equipment allows to collect source samples and analyze odour in a laboratory. Odour study in 2016 and 2017 with field olfactometer Scentroid SM100 and gas analyzer Gasmet DX-4030 in districts of Riga indicates that the highest concentrations of odour are in Bolderaja, Sarkandaugava, Kundzinsala, Mangalsala, Milgravis and Vecmilgravis. Study indicates that the highest odour concentrations, especially among producing companies can reach up to 6-7 odour units $\left(\mathrm{OU}_{E} / \mathrm{m}^{3}\right)$, however gas analyzer Gasmet $\mathrm{DX}-4030$ indicates oil products or carbon dioxide.
\end{abstract}

Keywords: gas analysis, odour, various districts of Riga.

\section{INTRODUCTION}

Different emission sources of odours become increasingly important environmental problem which may have a negative impact on human health and quality of life. Human odour perception may be subjective, however the odour perception threshold is considered to be the odorant concentration where at least half of odour assessor's group members confirm the existence of odour, and then it is $1 \mathrm{ou}_{\mathrm{E}} / \mathrm{m}^{3}$ [1]. Odour nuisance is such odour which causes negative effect on human well-being, and its threshold exceeds the odour perception threshold. The cause of the odour, its frequency, intensity, duration, hedonic tone (unpleasantness) and the nature of the location are of essential significance.

Nowadays, increasing attention is being paid to the odour emission studies both in the world $[2 ; 3 ; 4$; 5; 6] and Latvia [7]. Awareness-raising of these issues makes it easier identify the odour emission source, perform more effective control and eliminate faster nuisances caused by odours. Odour emission sources can be both diffuse sources and the point source. Odour emission sources may be pollution caused by the operation of companies such as oil product terminals, chemical plants, waste storage and composting sites, the operation of wastewater treatment plants, etc., however, odours can be caused also by physical persons which do not perform economic activities, for example, by discharging poorly treated or even untreated domestic wastewaters in the environment, during the heating season there is a smell of smoke in the air coming from the private houses, especially when coal is used as fuel.

Nowadays more and more advanced technologies such as electrochemical, metal oxides, photo ionization detectors or "electronic noses" are used to measure the odour concentration by help of which it is possible to make indicative odour concentration measurements on an ongoing basis, however, installations are stationary, they are set for recording a specific parameter (chemical substance). So far still the best odour indicator is a human nose, enabling to identify odour also according to the qualitative method principles.

\section{MATERIALS AND METHODS}

During the research, the odour concentration and the presence of airborne pollutants were determined by using the quantitative research method, i.e., a method for measuring the odour and pollutant concentration. During the research, the qualitative research method was also used; it is a method which indicates the presence of a substance and which helped identify which pollutants at the relevant time were in the air.

The odour concentration was determined by the Scentroid SM100 field olfactometer, and the presence and concentration of the pollutants in the air were determined by the gas analyzer Gasmet DX-4030. 


\section{Scentroid SM100 field olfactometer}

The Scentroid SM100 field olfactometer is designed both to measure the odour concentration from the emission sources and to collect the source samples in order to analyze them further in the laboratory [8]. The equipped field olfactometer uses high pressure odourless gas from a high pressure carbon fibre tank. The sample is drawn by help of vacuum generated by the diluted compressed air flow. The dilution ratio of fresh to ambient air is controlled through the patented Scentroid flow regulator valve (Fig. 1). The panel list offers 15 discreet dilution levels, the minimum dilution is 2 odour units, and the maximum - 30000 [9].

The studies carried out so far [10] indicate that the results obtained by the Scentroid SM100 field olfactometer in the field and stationary laboratory match satisfactory both for the point sources and diffuse sources.

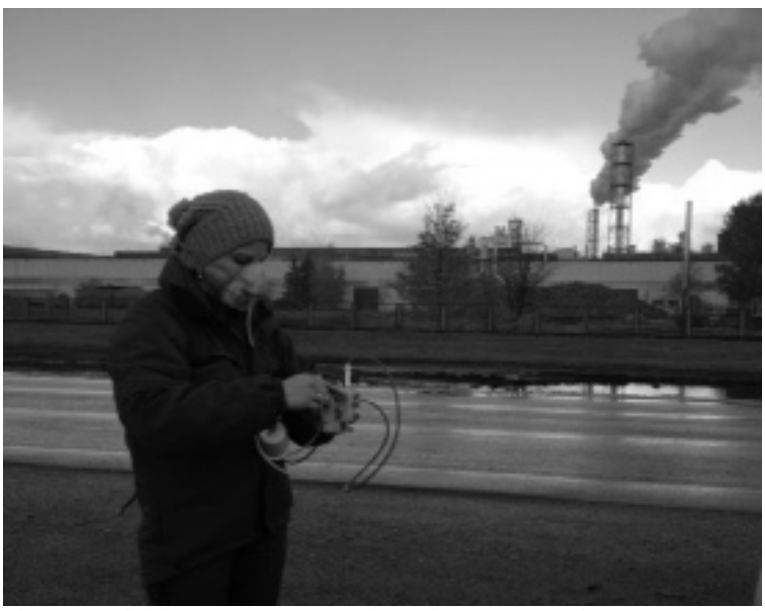

Fig. 1. Field measurements by the Scentroid SM100 field olfactometer.

Gasmet DX-4030 gas analyzer

Gasmet DX-4030 is a portable gas analyzer that can simultaneously identify 23 inorganic and organic gases such as carbon monoxide, carbon dioxide, methane, benzene, acids, aldehydes and other volatile vapours [11].

The Gasmet DX-4030 gas analyzer is controlled using Calcmet-Lite software which runs on the Windows Mobile platform [11]. The Gasmet DX4030 gas analyzer connects to Calcmet-Lite software by help of Bluetooth. The DX4030 analyser module houses a Fourier Transform Infrared (FTIR) spectrometer, Rhodium-Gold coated sample cell and signal processing electronics. The sample preparation is not needed, because sample gas is extracted into the sample cell via a probe with a built-in particle filter [11].

One can freely move using the Gasmet DX-4030 gas analyzer for making the measurements at different locations (Fig. 2).

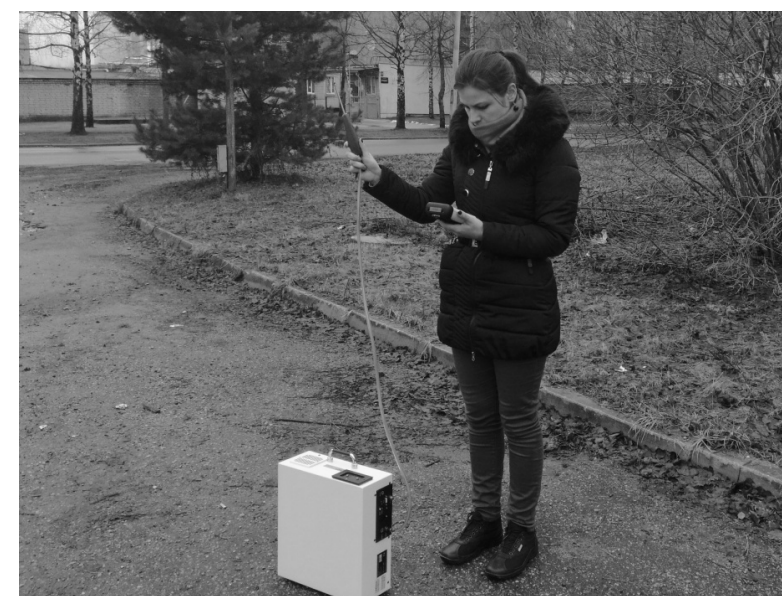

Fig. 2. Field measurements using the Gasmet DX-4030 gas analyzer.

The real time measurement results are displayed in Calcmet-Lite software, afterwards they are stored and transformed on the computer.

\section{RESULTS AND DISCUSSION}

The State Environmental Service performs the odour emission control in Latvia in accordance with the Cabinet Regulation No. 724 "Regulations Regarding the Methods for Determination of the Odours Caused by Polluting Activity, as well as the Procedures for Restricting the Spread of such Odours" of 25.11.2014. Likewise, the State Fire and Rescue Service receives calls from the inhabitants on odour nuisance in case of accidents or if there is suspicion of chemical leakage. Thus, to identify the areas where inhabitants feel odour nuisance, complaints received by the above institutions were summarized.

According to the information provided by the State Fire and Rescue Service, in 2012, 94 calls regarding odour nuisance were received in Riga of which the largest part, respectively, $79 \%$ or 74 calls were from Riga Northern suburban district. In 2013, there were 73 calls received in Riga of which 35 were from the Northern suburban district. In 2014 and 2015 , the number of calls regarding odour nuisance was similar - 35 and 34, of which, respectively, 23 and 14 were received from those living in the Northern suburban district.

In 2015, the State Environmental Service received in total in the whole Latvia 962 complaints of which 403 were from the administrative territory of Riga. In 2016, the number of complaints received in Latvia was higher than that of the previous year, respectively, 1087, however, the number of complaints within the territory of Riga has decreased in comparison to the previous year, respectively 384 complaints regarding odour nuisance. It has to be pointed out that the information provided by each person is recorded even if several complaints regarding one emission source are received per day or hour. 
In order to select the most suitable locations and time for measuring, the location and time of the respective event specified in the complaints were analysed.

Analysing the complaints regarding odour nuisance within the interval of 24 hours (Fig. 3), it can be concluded that the highest number of complaints in percentage was received during the period of time from 16:00 to 24:00, it means that people feel odour nuisance mostly directly at their homes.

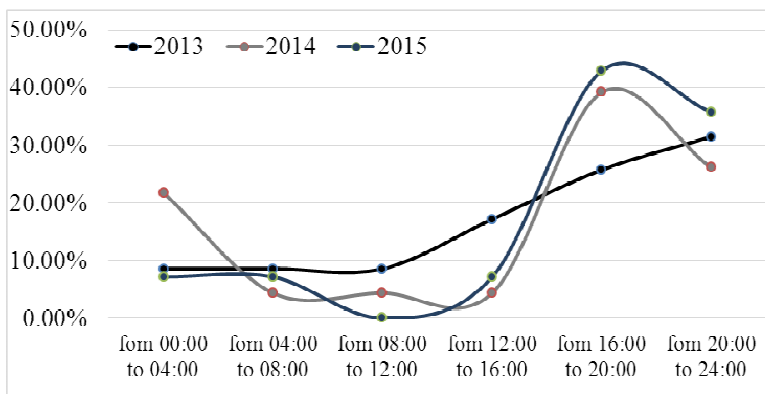

Fig. 3. Complaints within the interval of 24 hours in 2013, 2014 and 2015 (data source: the State Fire and Rescue Service).

Analysing complaints on odour nuisance within the monthly interval, Fig. 4, it can be seen that in 2012 the highest number of complaints were received exactly during the summer months. In 2013, 2014 and 2015 there were no significant differences observed within the interval of months, thus, it can be concluded that the number of the odour nuisance cases are equal in all seasons.

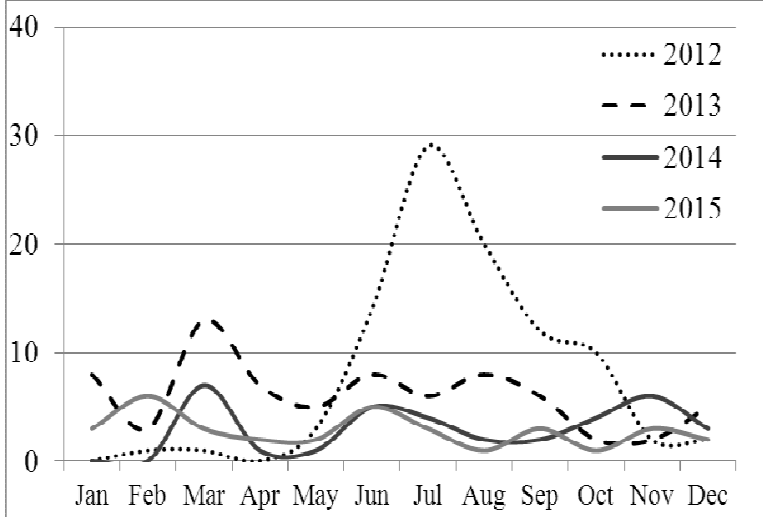

Fig. 4. Complaints at the monthly interval from 2012 to 2015 (data source: the State Fire and Rescue Service).

Analysing the data submitted by the inhabitants of Riga to the State Environmental Service in 2016, it was found that out of 384 complaints received within the administrative territory of Riga 272 complaints were from the inhabitants of seven micro districts, respectively, Bolderaja, Sarkandaugava, Kundzinsala, Mangalsala, Milgravis, Vecmilgravis and PetersalaAndrejsala (Fig. 5). The highest number of complaints was received from the inhabitants of Sarkandaugava, i.e., 74 complaints or $19 \%$ of all complaints received in Riga. 57 complaints or $15 \%$ of the number of complaints recorded within the administrative territory of Riga on odour nuisance were received from those living in Bolderaja. Similarly, there were also 53 complaints (which amounts to $14 \%$ of the total number of the complaints received on unpleasant odours) recorded in Milgravis. The number of complaints in the other districts of Riga does not exceed $10 \%$ of the total number of complaints received.

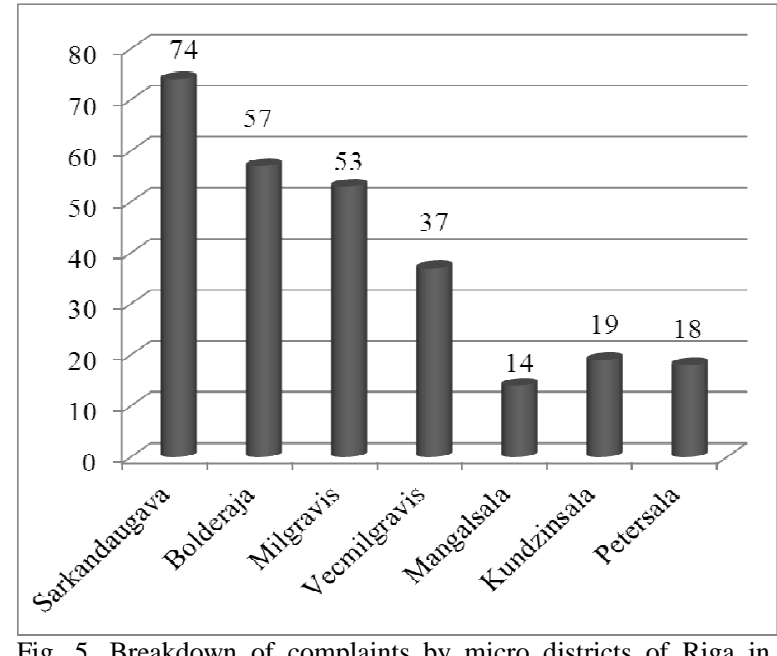

Fig. 5. Breakdown of complaints by micro districts of Riga in 2016.

1 to 5 complaints on unpleasant odours in 2016 were recorded in several micro districts of Riga such as Daugavgriva, Zolitude, Pleskodale, Tornkalns, Ciekurkalns, Darzini, Rumbula, etc. There are no complaints on odour nuisance recorded in several micro districts such as Skanste, Grizinkalns, Maskava suburb, Bukulti, Trisciems, Jaunciems, Katlakalns, Agenskalns, etc.

During the research, the data provided by the inhabitants on the odour quality were also analysed, i.e., which odours people can smell. The highest number of complaints was received on oil product odours, i.e., 147 complaints (Table 1) or $38 \%$ of the total number of complaints were received in 2016 (Fig. 6). A relatively large proportion of the complaints is about smoke odours, respectively, $26 \%$ (Fig. 6), it means that the State Environmental Service was notified 98 times on unpleasant odours and nuisance smoke odours during a year. The State Environmental Service, upon carrying out inspections regarding smoke odours, relatively seldom found violations of the environmental protection laws and regulations, i.e., burning of different waste at the properties owned by the companies or physical persons. Inspecting the territories of the companies and more often private house districts, it was, mainly, found that wet wood or coal is used as fuel causing unpleasant odours, however, the above fuels are allowed. 
Table 1.

Breakdown of the number of complaints by the type of odour nuisance in 2016.

\begin{tabular}{|c|c|}
\hline Type of odour & number of complaints \\
\hline oil products & 147 \\
\hline smoke & 98 \\
\hline sewerage & 39 \\
\hline chemicals & 36 \\
\hline paint / lacquer & 11 \\
\hline Metalworking & 7 \\
\hline plastic & 9 \\
\hline other & 37 \\
\hline Total & $\mathbf{3 8 4}$ \\
\hline
\end{tabular}

A relatively large number of complaints is received on sewerage odour nuisance, respectively, 39 complaints (Table 1 ) or $10 \%$ of the total number of complaints (Fig. 6). Despite the fact that the centralized sewerage network is provided for 95-97 $\%$ of the administrative territory of Riga, still a part of inhabitants of the private house areas, as well as the companies have their own biological treatment plants, or wastewater is collected in a decentralized manner. The reason for unpleasant sewerage odours is inadequately maintained treatment plants or overflowing exhaustible wells - it is failed to monitor the filling level of exhaustible wells.

In 2016, there were 36 complaints or $10 \%$ (Table 1) on chemical odours (Fig. 6) and 11 complaints or $9 \%$ on paint and lacquer odours. The emission sources of chemical substances and lacquers (often also adhesives) are the operation of such companies as various production facilities, service stations, wood impregnation companies, etc. Inhabitants often mention chemical odour although, in fact, the oil product odour is felt in the air.

Inhabitants have complained on the plastic odour 9 times and on the metal processing companies -7 times (Table 1).

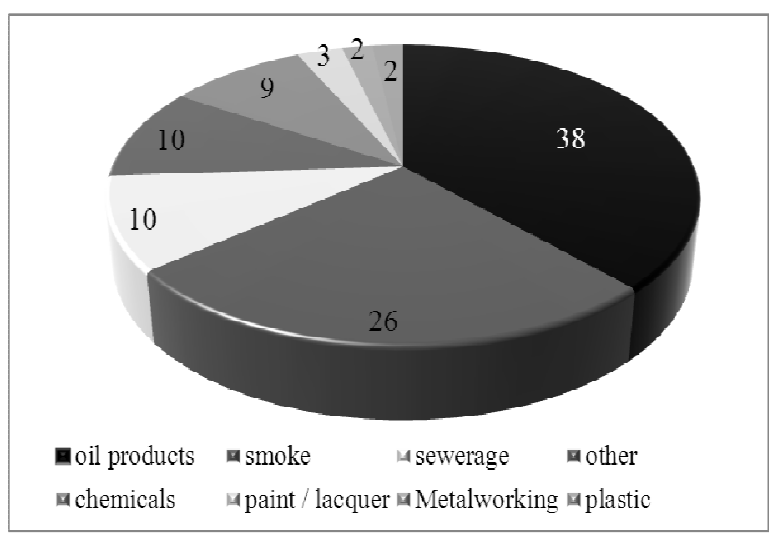

Fig. 6. Breakdown of complaints by types of odours in 2016.

Inhabitants relatively often -37 times or $10 \%-$ provided information on other odours (Fig. 6) such as odours of various foods from restaurants, cafes and fast food establishments, odour nuisance from the waste management sites, garbage containers at the residential houses if not removed on time, rubber odours from the vehicle racing tracks, odours from street repairs, as well as other types of odours.

During the research, the odour concentration study was carried out using the Scentroid SM100 field olfactometer in the micro districts of Riga where the highest number of complaints on the odour nuisance was reported. During the research from October 2016 to January 2017 almost all streets of Bolderaja, Daugavgriva, Voleri, Petersala-Andrejsala, Kundzinsala, Sarkandaugava, Milgravis, Vecmilgravis, Mangalsala, Vecdaugava and Vecaki were surveyed. During the survey, smoke, wood and oil product odours were found in Bolderaja, Vecmīlgrāvis and Sarkandaugava. Measuring odours, the odour concentration mainly was below 2 odour units. There were 3 units of odour found in the neighbourhoods of Ezera Street (Sarkandaugava) and Tvaika Street (Sarkandaugava). It has to be noted that while the measurements were made no complaints were received. The State Environmental Service, performing the inspection of the territory immediately after receiving the complaints on odour nuisance, found $6-7$ odour units $\left(\mathrm{ou}_{\mathrm{E}} / \mathrm{m}^{3}\right)$ in Bolderaja and Milgravis, such level of odour causes adverse impact on human wellbeing.

Table 2.

Substance concentration (ppm) in Sarkandaugava

\begin{tabular}{|c|l|c|c|c|}
\hline No & Address & Ezera 20 & $\begin{array}{c}\text { Ezera } \\
\text { Tvaika } \\
68\end{array}$ \\
\hline 1 & Carbon dioxide CO2 & 690 & 483 & 462 \\
\hline 2 & Carbon monoxide CO & 0 & 0 & 0 \\
\hline 3 & Nitrous oxide N2O & 0.25 & 0.19 & 0.2 \\
\hline 4 & Methane CH4 & 2.04 & 1.72 & 1.79 \\
\hline 5 & Propane C3H8 & 0.12 & 0.34 & 0 \\
\hline 6 & Butane C4H10 & 0 & 0.18 & 0.05 \\
\hline 7 & Acetylene C2H2 & 0.06 & 0 & 0.09 \\
\hline 8 & Benzene C6H6 & 0.23 & 0.03 & 0.07 \\
\hline 9 & Toluene C7H8 & 0.33 & 0.23 & 0.18 \\
\hline 10 & Acetic acid C2H4O2 & 0.7 & 0 & 0 \\
\hline 11 & Formaldehyde CHOH & 0 & 0 & 0 \\
\hline 12 & Acetone C3H6O & 0 & 0 & 0 \\
\hline 13 & Methanol CH4O & 0 & 0.18 & 0 \\
\hline 14 & Ethanol C2H6O & 0 & 0 & 0 \\
\hline 15 & tert-Butyl methyl ether & & & \\
\hline 16 & Acetonitrile C2H3N & 0 & 0 & 0 \\
\hline 17 & Nitromethane CH3NO2 & 0.93 & 0.43 & 0.56 \\
\hline 18 & Chloroform CHCl3 & 1.71 & 1.07 & 1.2 \\
\hline 19 & Chloroethene C2H3Cl & 0 & 0 & 0 \\
\hline 20 & Freon 134A C2H2F4 & 0 & 0 & 0 \\
\hline 21 & Ammonia NH3 & 0 & 0 & 0 \\
\hline 22 & Hydrogen chloride HCl & 0 & 0 & 0 \\
\hline 23 & Hydrogen cyanide HCN & 1.73 & 1.7 \\
\hline
\end{tabular}


On 29.01.2017, while measuring airborne substances with the Gasmet DX-4030 gas analyzer in Sarkandaugava, a high concentration of carbon dioxide was recorded, respectively, from 462 to 690 ppm (Table 2). It is interesting that previous measurements made on 17.12.2016 at those locations did not show such a high carbon dioxide concentration, respectively, from 0 to $15 \mathrm{ppm}$. Carbon dioxide and nitric oxide indicate the presence of smoke, respectively these substances are released in the air as a result of fuel combustion.

Benzene, toluol, acetylene indicate the presence of oil products, and it is only natural as the measurements were made relatively close to the oil product handling terminals.

While analysing gasses, the presence of other substances such as acetic acid, methanol, nitromethan, chloroform and hydrocyan was found.

\section{CONCLUSION}

Analysing the information provided by the inhabitants on odour nuisance, it can be concluded that the highest number of unpleasant odours are caused by the oil product handling terminals, therefore the highest number of complaints were received from Bolderaja, Sarkandaugava, Kundzinsala, Mangalsala, Milgravis, Vecmilgravis and Petersala-Andrejsala, where the unpleasant odours caused due to port operations spread to the neighbouring areas depending on the wind direction and speed.

The research results show that smoke, wood and oil product odours found in Bolderaja, Vecmilgavis un Sarkandaugava do not exceed 3 odour units $\left(\mathrm{ou}_{\mathrm{E}} / \mathrm{m}^{3}\right)$.

The analysis of gas confirms the nose-felt odours, respectively, smoke and oil product odours, however, other pollutants are also identified in such a concentration which can not be felt by a human nose.

Of course, mostly, odour emission sources are pollutants which are discharged into the air due to economic activities of the companies, however, physical persons due to their intentional actions or inactions also cause odour nuisance which can be eliminated by choosing more environmentally friendly fuel, cleaning the chimney and maintaining treatment plants on a regular basis, as well as by not tolerating waste accumulated.

\section{ACKNOWLEDGMENTS}

The author expresses her gratitude to the State Environmental Service for providing the information and to the State Environmental Service for providing the information and material support.

\section{REFERENCES}

[1] Republic of Latvia Cabinet Regulation No. 724 „Regulations Regarding the Methods for Determination of the Odours Caused by Polluting Activity, as well as the Procedures for Restricting the Spread of such Odours", 2014. Latvijas Vēstnesis, No. 250 (5310), 16.12.2014., Adopted 25.11.2014.

[2] Bokowa Anna H., 2010. Review of Odour Legislation, Chemical Engineering Transactions, Vol. 23. pp. 31 -36.

[3] Brattoli M., De Gennaro G., De Pinto V., Demarinis Loiotile A., Lovascio S., Penza M., 2011. Odour Detection Methods: Olfactometry and Chemical Sensors. Sensors. Vol. 11, pp. 5290-5322.

[4] Dravnieks A., Masurat T., Richard A. Lamm, 2012. Hedonics of Odors and Odor Descriptors, Journal of the Air Pollution Control Association pp. 752-755.

[5] Sironia S., Eusebioa L., Capellia L., Remondinib M., Del Rossoa R. 2014. Use of an Electronic Nose for Indoor Air Quality Monitoring, Chemical engieneering transactions, Vol. 40, pp. $73-78$.

[6] Zarra T., Reiser M., Naddeo V., Belgirno V., Kranert M., 2012. A comparative and Critical Evaluation of Sampling Marerials in the Measurement of Odour Concentratin by Dynamic Olfactometry, Chemical engieneering transactions, Vol. 30 (12), pp. 307-312.

[7] Kāla A., Beikulis O., Rubins J. 2015. Practical application of commercial ALPHA M.O.S. E-NOSE for air quality control in Riga. European Network on New Sensing Technologies for Air Pollution Control and Environmental Sustainability EuNetAir COST Action TD1105.

[8] Scentroid Model 110C. Operating and maintenance manual. 2012. IDES Canada Inc. Version 1.4.

[9] Scentroid Model 110. Operating and maintenance manual. 2013. IDES Canada Inc. Version 2.0.

[10] Bokowa Anna H., 2012. Ambient Odour Assessment Similarities and Differences, Chemical Engineering Transactions, Vol. 30.

[11] DX-4030 FTIR Gas Analyser Instruction and Operating Manual, $2009 . \quad$ URL: http://pembrokeinstruments.com/_download_pdf_897/_Pemb roke-PDF-Downloads/Gasmet-DX4030-ManualPembroke.pdf, Viewed: 22.10.2016. 